3. Veranlaßt đie Kultur im Läuseversuch nach WEIGL ${ }^{12}$ ) die typische Darmepithel-Infektion der Laus?

4. Immunisiert die Kultur Meerschweinchen gegen die Infektion mit Fleckfiebervirus?

5. Erzeugt die Kultur im Kaninchenversuch Agglutinine gegen den Stamm Proteus-X I9?

Auf keine dieser Fragen erhalten wir aus KuczYNSKIs neuer Arbeit eine bestimmte positive Antwort. Die kurze Angabe, daß ,,der antigene Charakter (bei Immunisierungsversuchen) in gewissem Grade erhalten bleibt", besagt wenig. Die mikroskopische Ahnlichkeit seiner Kulturen mit den RickettsienAbbildungen von WOLBACH, TOOD und PALEREY ${ }^{13}$ ) [aus deren Arbeit sich übrigens eine Bestätigung der von DiETrIcH und mir in der Laus gefundenen Fadenbildung der Rickettsia Prowazeki, die KuczysssxI ${ }^{14}$ ) früher als Proteusfäden ansprach, ergibt], sowie mit den Gebilden von LöwE, RITTER und BÄHR (deren Versuchsergebnisse noch der Bestätigung beđürfen) und den Kulturen der Rickettsia der Schaflaus beweist ebenfalls nichts. Solange das Verhalten der gezüchteten Mikroben nicht auch in bezug auf die obenerwähnten 5 Punlte näher geklärt ist, muß die Behauptung, die Rickettsia Prowazeki bzw. den Fleckfiebererreger gezüchtet zu haben, als verfrüht angesehen werden.

Literatur: 1) Med. Klinik 1920, Nr. 27-30, $-{ }^{2}$ ) Beri. klin. Wochenschr. I92 I, Nr. 51 u. 52 (S. I 54I). $-{ }^{3}$ ) Zeitschr. f. Hyg. u. Infektionskrankh. Bd. 93. I921. - 4) Berl, klin. Wochenschr. 1921, Nr. 5I. $-{ }^{5}$ ) Berl. klin. Wochenschr. S. I 54 I. $-{ }^{6}$ ) Klin. Wochenschr. 1922, Nr. 28. - ${ }^{7}$ ) Journ. A. M. A. I921, S. I967. $\left.{ }^{8}\right)$ Berl. klin. Wochenschr. 1917, S. 346, und Arch. f. Schiffs- u. Tropenhyg. Bd. 21. 1917. -9) Dtsch. med. Wochenschr. I917, Nr. 19. - 10) S. Referat in Lubarsch-OSTERTAG I9I9, Jg. I9. $\left.{ }^{11}\right)$ Zentralbl. f. Bakteriol. Bd. 87. I921. - ${ }^{12}$ ) s. Referat in OPPENHEIMER-RONA Bd. 5, H. I/2. I92 I. $-{ }^{13}$ ) The etiology and pathology of typhus. Cambridge, Mass. Igz2. - ${ }^{\text {t4}}$ ) Zentralbl. f. allg. Pathol. u. pathol. Anat. Bd. 29. 1918.

\section{ÜBER KÜNSTLICH ERZEUGTE GLYKOSURIEN UND IHRE BEWERTUNG FÜR DIE FRÜHDIAGNOSE DER GRAVIDITÄT IN DER PRAXIS.}

Bemerkungen zur gleichlautenden Arbeit von Karl Hellmuth. Klin. Wochenschr. 1922 Nr. 23.

Von

Dr. HeInZ KÜstNeR.

(Aus der Uaiv.-Frauenklinik zu Breslau. Dir. Geh. Med.-Rat Dr. O. Küstner.)

In seiner Arbeit berichtet HExIMUTH uber die Versuche, den während der Schwangerschaft bestehenden renalen Diabetes mit den von Frank und NothMANN, JOSEPH und KamNITZER und nach der Angabe Franks von Roubirschek ausgearbeiteten Methoden nachzuweisen. Ich möchte nur auf die letzte dieser Methoden eingehen. HeLlmuth hat nur 3 Frauen mit der Roubitschekschen Methode untersucht und bei allen 3 war, obwohl sie früh gravid waren, eine Zuckerausscheidung nicht zu konstatieren.

Ich habe bereits auf dem Gynäkologen-Kongreß in Innsbrucis über meine Untersuchungen, die auch demnächst im Zentralbl. $f$ Gynäkol. erscheinen werden, berichtet, möchte aber auf die Frage der Verwertbarkeit der Roubitschekschen Methode für die Praxis eingehen.

Meine Untersuchungen beziehen sich auf 125 Schwangere, von denen einige mehrfach untersucht sind, so daß ich an I 50 Fällen die zur Diskussion stchende Methode auf ihre Brauchbarkeit prüfen konnte. Bei soo dieser Frauen war im Urin nach etwa $3 / 4-5 / 4$ Stunden Zucker nachweisbar, bei 50 nicht. Diese 50 Fälle befanden sich alle im 8. bis Io. Schwangerschaftsmonat außer einer Frau, die 3 Monate gravid war und bei der einige Tage später Abort eintrat. Ich habe also mit dieser Methode während der Gravidität bis etwa zum 8. Monat, aber ganz besonders stark in den ersten Monaten eine Zuckerausscheidung durch die Nieren erzielen können.

In gewisser Weise bin ich von der Versuchsanordnung von Roubixscher abgewichen: Ich untersuchte die Frauen nicht in nüchternem Zustand. Da ich stets den Blutzuckerwert mehrmals bestimmte, so hatte ich immer eine Kontrolle, ob die Erhöhung des Blutzuckers in den physiologischen Grenzen sich hielt, maximal bis $0,19 \%$ anstieg. Ein höheres Ansteigen habe ich übrigens nie beobachtet. Ich möchte sogax annehmen, daß der Organismus in einer Hungerzeit von IO-I4 Stunden soviel von dem Glykogenvorrat der Leber gerade in der Schwangerschaft verbraucht, daß die Zufuhr von Io g Traubenzucker diesen Verlust nicht ausgleichen, und daß infolgedessen die Erhöhung des Blutzuckers auf die notwendigen Werte von $0,14-0,19 \%$ nach der Injektion von Adrenalin nicht eintreten kann.

Natütlich hat, wie jede biologische Methode, auch diese ihre schwachen Seiten und Fehlerquellen. So war manchmal das Adrenalin ans irgendwelchen Gründen nicht wirksam. In anderen Fällen war zu flach subcutan injiziert, oder vielleicht zufällig eine Vene getroffen. Im ersten Fall bleibt wegen der zu langsamen Resorption eine Reizung des Sympathicus aus, im zweiten Fall steigt die Blutzuckerkurve steil an, hällt sich aber nicht lange genug auf einer für den Versuch notwendigen mittleren Höhe.

Jedenfalls habe ich mich bei einem negativ ausfallenden Versuch nie beruhigt, sondern immer die Untersuchungen wiederholt. Bestand eine Gravidität, so bekam ich stets auch bei den zuerst negativen einen positiven Ausfall der Reaktion. Der Blutzuckerwert war dann das erstemal so wenig erhöht, daß selbst bei der Annahme und dem Bestehen eines renalen Diabetes Zucker durch die Nieren nicht ausgeschieden werden konnte.

Ich glaube, daß Hellmush, wenn er seine 3 Fälle, die auf Adrenalin negativ reagierten, einer weiteren Untersuchung unterzogen hätte, eine Erklärung für den negativen Ausfall gefunden und nicht der Methode die Schuld zugemessen hätte. Hellmutr scheint bei seinen Untersuchungen nicht den Blutzuckerwert bestimmt zu haben, jedenfalls wird davon nicht gesprochen. Ich halte die Blutuntersuchung vorläufig noch für unbedingt erforderlich, wenn es sich darum handelt, die Brauchbarkeit der Methoden für die Verwendung in der Praxis zu prüfen. Wichtig ist ferner eine Blutzuckerbestimmung gerade auch bei den zur Kontrolle verwandten nicht Schwangeren, um bei diesen Störungen im Kohlenhydratstoffwechsel anderer Provenienz ausschließen zu können. Die Bestimmung des Blutzuckers gibt uns ferner die Möglichkeit, durch geringe Ånderungen der Versuchsanordnungen - Steigerung der Traubenzuckermenge oder Injektion von etwas mehr Adrenalin - bei späteren Untersuchungen eine Glykosurie zu er zielen. Individuelle Verschiedenheiten spieien bei diesen Versuchen, wie bei allen biologischen Untersuchungen, eine wichtige Rolle.

Jedenfalls bin ich nach meinem großen Untersuchungsmaterial an Schwangeren und zahlreichen Kontrollen an Nichtgraviden $z u$ dem Resultat gekommen: Die Roubitscheksche Methode leistet in der Klinik ausgezeichnete Dienste, für die Praxis aber ist sie vorläufig noch nicht in der Weise $z \mathfrak{u}$ verwenden, daß das Auftreten von Zucker im Harn nach Injektion von $0,5 \mathrm{mg}$ Adrenalin unbedingt identisch mit der Diagnose "Schwangerschaft" ist; die Bestimmung des Blutzuckers ist dazu stets notwendig. Wir haben vorläufig noch keinen pharmakologischen Weg ohne Fehlerquellen den Blutzucker auf einen Wert zu bringen, der unter $0,2 \%$ aber über $0, \mathrm{I}_{3}$ bis $0,14 \%$ liegt; am ehesten erreichen wir dies noch mit der FrankNothmannschen Methode durch $Z_{u} u f u h r$ von Ioo $g$ Traubenzucker per os.

Wir minssen uns also vorlänfig bescheiden und den Blutzucker bestimmen, besonders, wenn es sich um Fragen der Brauchbarkeit der Methoden handelt.

\section{ERWIDERUNG. \\ Von}

Kari HELcmuth.

Die Nachprüfung der Roubitschekschen Methode hat sich bei der Verwertung unserer Ergebnisse, abgesehen von den 3 Frühgraviditäten, auf 62 Nichtgravide erstreckt.

Die Abweichung KÜstNERS von ROUBITSCHErs Originalversuchsanordnung, die Frauen nicht mehr im Nüchternzustand zu untersuchen, ist eine weitere Komplikation dieses noch vollig in der Diskussion stehendem Problems, da im Nichtnüchternzustand die Resorptionsbedingungen für den Traubenzucker je nach dem Füllungszustand des Magens ganz verschieden sind.

ROUBITSCHEK selbst betont am SchluB seiner Arbeit, daß Blutzuckerbestimmungen bei seiner Methode erwünscht, aber durchaus nicht nötig sind. Der $Z$ weck der Veröffentlichung unserer Ergebnisse wat, wie die Úberschrift unserer Arbeit klar zum Ausdruck brachte, die Nachprüfung der Frage, ob sich u. a. die Roubitscheksche Versuchsanordnung bei Einhalten ihrer Vorscirift tatsächlich als eine für den Praktiker geeignete Methode zur Frühdiagnose der Gravidität erweisen würde oder nicht. Diese Frage haben wir verneint, da die Methode bei drei aufeinanderfolgenden Fällen von Frühgravidität der ersten drei Monate versagte. Diese Versager genügen unseres Erachtens, die Roubitscheksche Methode in dieser Form als ungeeignet für die Praxis abzulehnen 
eine Tatsache, zu der Küstner am Schluß seiner Arbeit selbst kommt. Insoweit sind die KüsTNER schen Ausführungen also durchaus eine Bestätigung unserer Ergebnisse.

Bei den vorgeschlagenen Wiederholungen der Probe an der gleichen Patientin geben wir folgendes zu bedenken: Einwandsfreie Wiederholungen müssen die in unserer Arbeit bereits betonten ARNOLDIschen Befunde berücksichtigen. Sodann, was soll der Praktiker mit derartigen Schwankungen der Ergebnisse bei der ersten und zweiten Untersuchung, für die KüsTNER eine befriedigende Erklärung auch nicht bringen kann, anfangen? Soll er das positive oder negative Ergebnis verwerten?

Die Ursache für die einander widersprechenden Ergebnisse könnte vielleicht in einer verschiedenenWirksamkeit der verwandten Adrenalinpräparate liegen. Wir betonen, daß wir genau der Roubitschekschen Vorschrift entsprechend die Suprareninlösung I : I OOO Höchst verwandt haben. Ließen sich für diesen Verdacht Anhaltspunkte gewinnen, so würde es sich um eine Fehlerquelle handeln, deren Ausschaltung für den Praktiker überhaupt nicht möglich ist.

Im übrigen verweisen wir auf die Ergebnisse, die kürzlich von DIETRICH aus der Göttinger Frauenklinik in Nr. 28 dieser Wochenschrift veröffentlicht sind. Auch DIETRICH hält auf Grund seiner Ergebnisse die Roubitscheksche Methode für unbrauchbar für die Diagnose der Gravidität.

\section{KURZE WISSENSCHAFTLICHE MITTEILUNGEN.}

\section{ÜBER DEN IONENAUSTAUSCH ZWISCHEN BIUT- KÖRPERCHEN UND SERUM 1 \%. \\ Von}

KLOTHILdE MEIER.

Der Ionenaustausch zwischen Blutkörperchen and Serum ist in hohem Maße abhängig von der Reaktion des Blutes. Gibt man zu Gesamtblut Kohlensäure in steigender Menge, trennt dann bei den jeweiligen Spannungen Blutkörperchen und Serum voneinander und untersucht das Kohlensäurebindungsvermögen des Blutes, so findet man, daß das Kohlensäurebindungsvermögen, also damit auch der Alkaligehalt des Serums, der zu dieser Kohlensäurebindung zur Verfügung gestellt wird, sehr stark zunimmt. Nun vermindert sich im Serum mit steigender Kohlensäurespannung der Chlorgehalt durch Abwanderung des Chlors in die Blutkörperchen. Genaue Berechnung der molaren Alkalizunahme im Serum und der molaren Chlorabnahme und Vergleich der beiden Werte ergibt, daß das zur Kohlensäurebindung zur Verfügung gestellte Alkali im Serum größer ist als die Alkalimenge, die durch die Chlorabwanderung frei wird. Es ergibt sich also ein zunächst ungeklärtes Alkalidefizit. Wahrscheinlich wird dieses durch eine Alkaliwanderung aus den Blutkörperchen in das Serum gedeckt. Die Größe dieser Alkalimenge läßt sich für jede Kohlensäurespannung berechnen. Gleichzeitig mit dieser Ionenwanderung findet eine Wasserverschiebung zwischen Blutkörperchen und Serum statt, nämlich ein Wassereinstrom aus dem Serum in die Körperchen, deren Volumen zunimmt, während die Serumdichte steigt. Das Maximum der Ionenwanderung und der Wasserverschiebung zwischen Körperchen und Serum, also auch das der Volumzunahme der Körperchen und der Serumeindickung liegt bei bestimmten, für alle Verschiebungen gleichen Reaktionen, ebenso wie Anderungen im kryoskopischen Verhalten des Serums. (Aus der medizinischen Klinik in Greifswald.)

\section{ÜBER DEN MECHANISMUS DES TRYPANOZIDIE- SCHWUNDES BEI LEBERKRANKEN MENSCHEN Von}

F. Rosenthal und R. Freund.

Im Anschluß an die früher dargelegten Beziehungen zwischen schweren diffusen Erkrankungen des Leberparenchyms und dem trypanoziden Titer des menschlichen Serums (Berl. klin. Wochenschr. I92 I, Nr. I6 u. 37) wurde die Frage experimentell untersucht, ob dem Schwunde der trypanoziden Serumsubstanz bei cholämischen Ikterusformen ein Zerstörungsproze $\beta$ durch Gallenbestandteile oder andere Substanzen des cholämischen Serums zugrunde liegt, oder ob der Absturz des trypanoziden Titers im Serum auf Störungen des Bildungsprozesses in den Produktionsstätten der trypanoziden Serumlxörper primär beruht. Folgende experimentelle Befunde sprechen in dem letzteren Sinne:

I. In Konzentrationen, die selbst maximalen, im ikterischen Serum verwirklichten Werten entsprechen, vermögen weder Galle noch Gallenbestandteile, insbesondere die gallensauren Salze die trypanozide Wirkung des normalen menschlichen Serums in nennenswertem Maße zu beeinträchtigen.

1) Erscheint ausf. in d. Zeitschr. f. d. ges. exp. 'Med.
2. Auch nach Mischung mit ikterischem Serum, das im Tierversuch unwirksam ist, bewahrt das normale menschliche Serum gegenüber der experimentellen Trypanosomeninfektion ungehindert seine therapeutischen Eigenschaften (vgl. auch ZEISS).

3. Auch im cholämischen Medium der mit Ikterogen vergifteten, schwer ikterischen Maus erfährt trotz des tagelangen Kontaktes der trypanoziden Serumsubstanz mit allen für eine direkte Zerstörung in Frage kommenden Stoffen das menschliche Normalserum keine Einbuße seiner therapeutischen Kraft.

Die Reaktion des Trypanozidieschwundes bei schweren menschlichen Leberkrankheiten, insbesondere bei den ausgeprägten cholämischen Ikterusformen hat mit den unter pathologischen Verhältnissen anzutreffenden Schwankungen des Komplementgehaltes nichts zu tun. Weder besteht ein Parallelismus zwischen der Reaktion des Trypanozidieschwundes und einer Komplementverarmung des Serums, noch kommt entgegen den Anschauungen LANGES (Klin. Wochenschrift I922, Nr. 2I/22) der trypanoziden Serumsubstanz ein komplexer Bau $\mathrm{zu}$, wie in mannigfach variierten Versuchen gezeigt werden konnte. Die Einwände LANGEs gegen die gesicherten engen Beziehungen zwischen dem trypanoziden Titer des menschlichen Serums und dem Funktionszustande der menschlichen Leber sind als nicht stichhaltig abzulehnen. Die ausführliche Arbeit erscheint in der Zeitschrift für Hygiene und Infektionskrankheiten. (Aus der Medizinischen Klinite der Universität Breslau).

\section{EIN MIKROVERFAHREN}

\section{ZUR QUANTITATIVEN BESTIMMUNG DES ACETONS UND DER $\beta$-OXYBUTTERSÄURE IM BLUT OHNE VENENPUNKTION. \\ Von}

ALFRED LÜBLIN.

Mit einer Capillarpipette von $0,2 \mathrm{ccm}$ Inhalt oder zwei Pipetten von o, I ccm Inhalt (siehe Pincussen : Mikromethodik) werden $0,2 \mathrm{ccm}$ Blut aus der Fingerbeere (evtl. nach leichter Stauung des Fingers) entnommen und in ein Zentrifugenspitzgläschen gespritzt, in dem sich $0,8 \mathrm{ccm}$ Wasser befindet. Zur EnteiweiBung werden $0,3 \mathrm{ccm} 2 / 3 \mathrm{n}$-Schwefelsäure + $0,3 \mathrm{ccm}(10 \%) \mathrm{Na}$. wolframat.-Lösung (Folin und $\mathrm{Wu}$ ) gefügt. Durchschütteln, mit einem Korkstopfen verschließen, $\quad \mathbf{I}^{\mathbf{1}} / \mathbf{2}$ Minuten auf einer kleinen elektrischen Zentrifuge scharf zentrifugieren. Das klare Filtrat wird in ein Widalröhrchen gegossen und davon $0,75 \mathrm{ccm}(=0,09 \mathrm{Blut})$ in einen 50 ccm-Mikrokjeldahlkolben überführt. Dazu kommen 25,0 Wasser $+\mathrm{I}, \mathrm{O}(\mathrm{IO} \%)$ Essigsäure + eine Spur Talkum. Am Mikrokjeldahlapparat wird (siehe LubLin: Ein neues Mikroverfahren zur getrennten quantitativen Bestimmung des Acetons und der $\beta$-Oxybuttersäure im Harn; Klin. Wochenschr. Nr. I8, S. 894) unter Zugrundelegung des Prinzips von Shaffer und EngFeld to Minuten lang in eine Vorlage (Erlenmeyerkölbchen von Ioo ccm Inhalt, das mit I5.0 Wi ser $+5,0^{\mathrm{n}} / 200^{-}$Jodlösung $+2,0(25 \%)$ Natronlauge beschickt ist) mit niedriger Flamme destilliert. Darauf werden nach Vertauschen der Vorlage A gegen eine in gleicher Vorlage beschickte Vorlage $B$ bei unverändert bestehender Flamme aus einem kleinen Scheidetrichter 20,0 Kaliumbichromatschwefel- 